\title{
The EFL Teachers' Perceptions of Teacher Identity: A Survey of Zhuangang and Non-zhuangang Primary School Teachers in China
}

\author{
Tao Xiong ${ }^{1,2} \&$ Xiuzhen Xiong ${ }^{1}$ \\ ${ }^{1}$ School of English and Education, Guangdong University of Foreign Studies, Guangzhou, China \\ ${ }^{2}$ National Key Research Center for Linguistics and Applied Linguistics, Guangdong University of Foreign \\ Studies, Guangzhou, China \\ Correspondence: Xiuzhen Xiong, School of English and Education, Guangdong University of Foreign Studies. \\ 178, Waihuan Donglu, Guangzhou Higher Education Mega Center, Guangzhou 510630, China. Tel: \\ 86-203-932-8837. E-mail: 20160910005@gdufs.edu.cn
}

Received: February 17, 2017 Accepted: March 12, 2017 Online Published: March 14, 2017

doi: 10.5539/elt.v10n4p100 URL: http://doi.org/10.5539/elt.v10n4p100

\begin{abstract}
Zhuangang (literally means "transferring post") English teachers, usually in the primary schools of rural areas in China, refer to the English teachers who used to teach school subjects other than English. Some of them may at the same time still teach other subjects in addition to English. They are a part of the solutions to the shortage of English teachers due to the policy of popularizing English learning in primary schools in China in 2001. Although they account for a large percentage of primary English teachers especially in rural areas in China, relatively little research has been conducted to investigate the status of their professional development and identity. This study is aimed at finding out whether there is a significant difference between zhuangang and non-zhuangang English teachers in their perceptions of teacher identity and if it is the case, what may be the contributing reasons. A questionnaire was allocated and a significant difference $(\mathrm{p}=0.005)$ was observed between zhuangang and non-zhuangang English teachers in their perceptions of teacher identity. Implications for enhancing their teacher identity and professional development are also discussed.
\end{abstract}

Keywords: China, zhuangang English teachers, teacher identity, teacher development

\section{Introduction}

Zhuangang (literally means "transferring post") English Teachers, usually in the primary schools of rural areas in China, refer to the English teachers who used to teach school subjects other than English. In addition to English, some of them may at the same time still teach other subjects, including Chinese, mathematics and the like. As part of the solutions to the shortage of English teacher due to the policy of popularizing English learning in primary schools in China in 2001, more than fifty percent of the English teachers in 2008 were zhuangang English teachers (Wang, 2008). Li (2012) stated that zhuangang English teachers accounted for $57 \%$ of all the English teachers in North China's Liaocheng city. According to You's (2016) study exploring new models of teacher development for zhuanang English teachers in rural areas, zhuangang English teachers still account for $32.5 \%$ of the whole group of primary school English teachers of Heyuan city in Guangdong province. This means nowadays there still exist a considerable number of zhuangang English teachers, but research done about them is rarely seen. They deserve much more attention from the researchers. This paper attempts to explore the demographic profile of zhuangang English teachers in Kaiping, a county in South China's Guangdong Province and to find out whether there is a significant difference in their perceptions of their teacher identity of being English teachers between zhuangang and non-zhuangang English teachers.

Teacher identity refers to the different cultural and social roles that teacher-learners enact while they are interacting with lecturers or other students during their course of learning (Richards, 2008). Dimensions of identity may include personal identity, situated or socially located identity and professional identity (Day \& Kington, 2008). And these dimensions were modified by Xun, Sun and Peng (2014)into four, namely career identity, major identity, personal identity and situated identity. Researchers believe that rather than being static, professional identity is a gradually changing and ongoing process of combination of the personal and professional sides of becoming and being a teacher (Beijaard, Meijer, \& Verloop, 2004). Elsewhere, it is argued that identity may be affected by professional life phases, job commitment, personal resilience and effectiveness 
(Day, 2011). The foreign language teachers' identity issue is becoming increasingly vital in that it is an important key to ensuring the teachers' commitment to their work and adherence to professional norm (Hammerness, Darling-hammond, \& Bransford, 2005). Standing at the core of teaching profession, teacher professional identity helps the EFL teachers to shape their own view about "how to act", "how to be" and "how to understand" their job and role in both school and society (Beauchamp \& Thomas, 2009, p. 178). Therefore, research helping EFL teachers to understand their identity is becoming more and more significant. The present study attempts to answer the following three questions:

1) What is the demographic profile of zhuangang English teachers in Kaiping?

2) Is there a significant difference between zhuangang and non-zhuangang English teachers in their perceptions of their teacher identity?

3) If there is a significant difference, what may be the possible reasons for it?

In the following, this paper will explore the relevant background of the current study, and present a literature review, followed by the main research.

\section{Background}

To modernize the education in China and to cater to the economic and cultural globalization in the $21^{\text {st }}$ century, the Chinese Ministry of Education (MOE) has taken two measures. First, a document called The Guidance to Promote the Initiation of English Teaching in Primary Schools (hereinafter referred to as the Guidance) was initiated, requiring all the primary schools, in urban and rural areas alike, to start English courses from Grade three or even earlier if possible (MOE, 2001). Second, a curriculum reform of basic education, also beginning in 2001, was started to change the teacher-centered teaching model to the students-centered one. The Guidelines for Curriculum Reform of Basic Education point out that the curriculum should focus on cultivating the students' comprehensive ability instead of rote learning or examination-oriented learning. Besides, the policy encouraged teachers to adopt task-based language teaching in classes so that students' language proficiency can be improved (MOE, 2001).

Those two efforts made by the MOE were crowned with success for improving Chinese citizens' English literacy and preparing China in the context of economic and cultural globalization with increasing demand for talents with high proficiency in English. However, initiating English teaching in the primary schools nationwide brought about a series of problems, among which the shortage of English teachers is one of the most severe ones. Moreover, the curriculum reform results in higher requirements for the quality of teachers. The Guidance states that to strengthen the quality of primary English teaching staff, more attention and consideration should be given to the training of outstanding teachers. Meanwhile, for those primary teachers of other subjects, they can participate in an English training program, get a certificate for their English proficiency level and take English courses in the primary schools (MOE, 2001), which is actually known as the origin of zhuangang English teachers. However, according to Dong (2003), for all the 1076 teachers taking part in the training program in Guangdong province in 2001 , only $53 \%$ of them passed the examination, and $36 \%$ of them were still allowed to take English courses without getting the certificate from the training program. Namely, 36\% of zhuangang English teachers at that time were not qualified for that job.

\subsection{Debate on the Necessity to Start English Teaching in Primary Schools}

Since the initiation of the policy of popularizing English teaching in primary schools nationwide in 2001, there appeared a heated debate among researchers and practitioners in English language education. Some of them supported the policy while others doubted the necessity. The debate mainly focused on the best starting age for learning a foreign language and the problem of teacher qualification. Since the first issue on learning age is a very complex one and beyond the scope of the current paper, here we mainly concentrate on the issue of teacher qualification.

Most of the reservations about the idea of lowering the starting age of English learning and teaching come from the concern about the inadequate quality of English teachers. On the reform of English teaching, Shu (2001)recommended that the popularization of English teaching in primary schools should be delayed to an appropriate time when the quantity and quality of English teachers reach a suitable level by training. Through analyzing the necessity and validation of starting English teaching in primary schools, Dong (2003) came to the conclusion that most of the primary schools were not actually ready for an early start of foreign language teaching because of a serious lack of qualified teachers and English teacher education was the most important task for current education policy. She also held that ignoring the problem of English teachers and starting English teaching in primary schools nationwide not only is a waste of education resources but may also dampen 
students' enthusiasm for English learning. Besides, Peng (2003) argued that given the quality of teachers and other resources available to primary schools in China, the theoretical bases and the practical feasibility of teaching English to primary school pupils are questionable.

Those who were in support of the policy, however, also have their own justifications. Wang (2010) stated that almost all countries have consensus about the value of having foreign language courses in primary schools. And from the aspect of the significance of English learning and children's learning characteristics, popularizing English teaching in primary schools has its objective necessity (Wan, 2014). What's more, Han and Liu (2008) contended that China's policy of popularizing English teaching is justifiable since it exemplifies the government's attitude of being open to the outside and determination of integration with the whole world.

\subsection{Current Situation and Problems That Still Exist}

Fifteen years having passed, with the smooth process of popularizing English teaching, the debate over its necessity has come to an end gradually. Till now, popularizing English teaching in primary schools in China have already become a reality. However, the problems of teacher qualification and development remain to be settled. Firstly, zhuangang English teachers still account for a large percent of English teachers in the rural areas. For the concern of educational equality and justice of social competition, English education in the primary schools of rural areas deserves more of our consideration (Zhang, 2005). The quality of teachers is the key to ensuring the success of primary education curriculum reform. Nevertheless, a considerable proportion of the teachers, especially zhuangang English teachers, are not up to the standard both theoretically and practically. On the one hand, it is difficult for teachers to shift their conventional pedagogical beliefs and teaching approaches. With traditional views deeply entrenched in their mind, they become disoriented while facing the new curriculum reform. On the other hand, the new curriculum standard puts forward higher requirements for the teachers' comprehensive competencies. Many teachers are in a lack of pedagogical approaches and have no idea about how to apply theories to practices (Yu, 2011).

Against this backdrop, it is of great significance for researchers to pay attention to the identity and professional development situation of zhuangang English teachers in rural areas.

\section{Literature Review}

\subsection{Teacher identity and teacher education}

Teacher identity has been widely discussed in recent years in general education (Xu, 2014). It is viewed as "an important analytic tool for understanding schools and society" in the fast changing and highly dependent global world (Gee, 2000, p. 99), and utilized as a frame or analytical lens through which aspects of teaching can be explored (Beauchamp \& Thomas, 2009). Because identity is not an external object visible to the naked eye but rather a sense of being (Han, 2016), it is difficult to conceptualize this concept and there is no unified single definition of identity that is accepted by the researchers. Nevertheless, most of the researchers see identity as a changing process. McLean (1999) suggests that teachers' sense of themselves shifts with "new social contexts, new questions and new ideas". Trent (2012) suggests that identities are negotiated and renegotiated in social situations and contexts of which social organizations such as schools, cultural products, language and knowledge, are a part.

In comparison with the fruitful research in many topics of general education, interest in identity issues in English language education has been relatively new. There are three main themes of related research which includes the relationship between teachers' linguistic positions and professional identity, conflicts between social and professional identities and how teacher identity is mediated in educational reforms (Xu, 2014). Day, Kington, Stobart and Sammons (2006) posit that teachers in most of the countries around the world are experiencing similar government interventions or policy shifts and the change coming along with it not only influences teachers' work but how teachers feel about their work. According to them, although reforms in schools are different in different countries in aspects of their content, direction and pace, one of the common characteristics of them is that the schools do not always pay enough attention to the teachers' work, lives and identities which play an important role in the teachers' motivation, efficacy, commitment, job satisfaction and effectiveness. To figure out whether an educational policy or curriculum reform will end up with success or failure, however, exploration of the teachers' identity and situation is necessary since it is teachers who are active participants along the process of reform (Han, 2016).

Apart from the three main themes listed by $\mathrm{Xu}$ (2014), another theme that appears frequently in the literature is the relationship between teacher identity and teacher education. As an important contributing factor to high-quality teaching, teacher education is vital for the success of other reforms urged on schools 
(Darling-Hammond, 2006). According to Abednia (2012), if the TESOL education program aims to help teachers act as transformative intellectuals, it should offer them the opportunity to construct or reconstruct their teacher identities since what teachers know and the way they think determine how they will behave in the classrooms. Through an overview of issues in the literature, Beauchamp and Thomas (2009) concluded that teachers' identity develops along with their own teaching practices, and that a teacher education program is an ideal starting point for building their awareness of developing their identity. Therefore, the organizers of a teacher education program should strive to incorporate what has been known about the context so that teachers will be prepared for the challenges that they may encounter in developing their positive professional identities. In regards to second language teacher education, Richards (2008) argues that teacher education is not only about knowledge acquisition and teaching skills building but also the real deep meaning about being a language teacher.

In the aspect of research method, most of the studies utilize the method of case study, ethnography and theoretical analysis. For example, Tsui (2007) explores teachers' identity construction through an enquiry of an EFL teacher's narrative storytelling about his being an English teacher throughout his six years of teaching. The paper authored by Farrell (2011) reports on the formation of professional identity of three experienced teachers through analysis of the data coming from the author's regular meetings with them. Besides, some other studies (Ha, 2007; Yang \& Bautista, 2008; Namaghi, 2009) investigated teacher identity from the qualitative approach. Elsewhere, Ajayi (2011) used a questionnaire to look into the relationship between socio-cultural identities and pedagogical practices of 57 high school teachers in Los Angeles, relatively few studies examine the teacher identity issue in quantitative way.

\subsection{Zhuangang English Teachers}

In contrast with the abundance in the research on foreign language teacher education and development, relatively little has been reported on the zhuangang English teachers' identity and professional development in China. A searching of the CNKI database, the most comprehensive and authoritative database for the research literature in Chinese found only fifteen articles concerned with primary zhuangang English teachers and the years of publication range from 2003 to 2016. These studies are mostly concerned with the issue of training for primary zhuangang English teachers. Several authors mentioned the unsatisfactory pronunciation of zhuangang English teachers, stating that English teachers' pronunciation directly affects the pupils' interest and learning effectiveness and training of their pronunciation should be strengthened (Chen, 2003; Xiao, 2012; Liu, 2009). The others proposed strategies and models of training zhuangang English teachers, suggesting ideas such as extending the duration of training, using the actual textbooks used in the primary schools during the training, and making use of the distance education technologies (Liu, 2008; Rao, 2011; Li, 2012).

\section{Research Design}

A questionnaire examining teacher identity was distributed to 300 primary English teachers in Kaiping county of Guangdong province, south China through an online survey platform and 182 teachers responded to the survey. The grades they teach range from Grade three to Grade six (Table 1). Among the 182 English teachers, 12 are male, accounting for $6.6 \%$ of the total population. Their years of teaching experience vary from novice teachers to experienced teachers and the detail can be seen in table 2. As for their academic preparations, $152(83.5 \%)$ of them have bachelor's degree (part-time), 27 (14.8\%) of them graduated from post-secondary institutions and the other 3 graduated from secondary normal/teacher schools.

The questionnaire was adapted from a questionnaire invented by Xun et al. (2014) which aims at measuring high school English teachers' identity status. Based on a literature review, Xun et al. (2014) formulated this questionnaire and tested it through exploratory confirmatory analysis. The questionnaire includes two parts: the first part is mainly about the participants' basic information including age, gender, years of teaching experience and the grades they teach; the second part, which is the main part of the questionnaire, includes 34 items exploring the teachers' career identity, major identity, situated identity and personal identity respectively. For each item, the participants are invited to choose from a 5-point Likert scale ranging from "strongly disagree" (1) to "strongly agree" (5). According to Xun et al.'s (2014) examination, the questionnaire is credited with fine reliability. Therefore, we believe this questionnaire can be used for large sample empirical investigation of EFL teacher identity. The higher the total score of the 34 items of the questionnaire, the stronger one's identity is. And it is the same case for single items. Although the inventory made by Xun et al. (2014) is customized for high school English teachers, with primary school and high school education having a lot in common, the authors changed all the terms "high school" into "primary school" so that the participants are able to choose the answer that fits their situation.

Finally, to figure out whether there is a significant difference between zhuangang and non-zhuangang English 
teachers in their perceptions of identity, the authors input the data obtained into SPSS 20 for an independent T-test, followed by T-tests for each item in the questionnaire to find out whether differences exist in different aspects.

Table 1. Grades that the English teachers teach

\begin{tabular}{lll}
\hline Grade & Population & Rate (\%) \\
\hline Grade 3 & 47 & 25.8 \\
Grade 4 & 42 & 23.2 \\
Grade 5 & 41 & 22.5 \\
Grade 6 & 41 & 22.5 \\
Grade 3 \& 4 & 1 & 0.5 \\
Grade 3 \& 5 & 4 & 2.2 \\
Grade 4 \& 5 & 2 & 1.1 \\
Grade 4 \& 6 & 4 & 2.2
\end{tabular}

Note. " $3 \& 4$ " means the teacher takes courses of Grade 3 and Grade 4 in the same semester; it is the same for " 3 $\& 5 ", " 4 \& 5$ " and "4 \& 6".

Table 2. Years of teaching experience

\begin{tabular}{lll}
\hline Years of teaching & Population & Rate $(\%)$ \\
\hline $0-3$ & 2 & 6.5 \\
$4-7$ & 2 & 2.8 \\
$8-15$ & 15 & 41.2 \\
$16-23$ & 34 & 42.3 \\
$24-30$ & 7 & 4.9 \\
$31+$ & 1 & 2.3 \\
\hline
\end{tabular}

\section{Results}

\subsection{Demographic Profile of Zhuangang English Teachers}

Among the 182 participants, 61 of them are zhuangang English teachers, accounting for $1 / 3$ of the total number. 7 of them are male and the other 54 are female. In terms of academic preparation, 43 (70.5\%) of them have bachelor's degree and $16(26.2 \%)$ of them graduated from post-secondary institutions. The grades they teach and their years of teaching are shown in table 3 and table 4 in detail respectively.

Table 3. Grades that zhuangang English teachers teach

\begin{tabular}{lll}
\hline Grade & Population & Rate (\%) \\
\hline Grade 3 & 15 & 24.6 \\
Grade 4 & 18 & 29.5 \\
Grade 5 & 15 & 24.6 \\
Grade 6 & 11 & 18.1 \\
Grade $3 \& 4$ & 1 & 1.6 \\
Grade 4 \& 5 & 1 & 1.6 \\
\hline
\end{tabular}

Note. " 3 \& 4" means the teacher teaches Grade 3 and Grade 4 in the same semester; it is the same for " 4 \& 5". 
Table 4. Zhuangang English teachers' years of teaching

\begin{tabular}{lll}
\hline Years of teaching & Population & Rate $(\%)$ \\
\hline $0-3$ & 2 & 3.3 \\
$4-7$ & 2 & 3.3 \\
$8-15$ & 15 & 24.6 \\
$16-23$ & 34 & 55.7 \\
$24-30$ & 7 & 11.5 \\
$31+$ & 1 & 1.6 \\
\hline
\end{tabular}

5.2 Comparison of Perceptions of Professional Identity between Zhuangang and Non-zhuangang English Teachers

Through an analysis of the total score of the 34 items in the questionnaire, a significant difference $(\mathrm{P}=0.005)$ of the perceptions of their professional identity was observed between zhuangangand non-zhuangang English teachers. The mean of the total score of zhuangang English teachers is 138.48 while that of the non-zhuangang English teachers is 148.03. After a respective analysis of the 34 items, it is found that 9 of them have significant difference, which can be seen in table 5 .

Table 5. The 9 items where significant difference exists between zhuangang and non-zhuangang English teachers

\begin{tabular}{|c|c|c|c|c|}
\hline Item & Content & $\begin{array}{l}\text { Mean of zhuangang } \\
\text { Englsih teachers }\end{array}$ & $\begin{array}{l}\text { Mean of non-zhuangang } \\
\text { English teachers }\end{array}$ & sig \\
\hline 3 & $\begin{array}{l}\text { When making self-introductions, I am pleased } \\
\text { to say that I am an English teacher. }\end{array}$ & 3.69 & 4.41 & 0.000 \\
\hline 8 & $\begin{array}{l}\text { I care about others' view about English } \\
\text { teachers. }\end{array}$ & 3.92 & 4.38 & 0.003 \\
\hline 14 & $\begin{array}{l}\text { Knowing about English-speaking countries' } \\
\text { culture is a necessity to learn English well. }\end{array}$ & 4.11 & 4.59 & 0.001 \\
\hline 15 & $\begin{array}{l}\text { English learning is a process of knowledge } \\
\text { construction. }\end{array}$ & 4.15 & 4.57 & 0.004 \\
\hline 18 & $\begin{array}{l}\text { I take primary school pupils' learning } \\
\text { characteristics into consideration in my } \\
\text { teaching practice. }\end{array}$ & 4.33 & 4.61 & 0.031 \\
\hline 30 & $\begin{array}{l}\text { English teaching in the primary school has the } \\
\text { subject's own characteristics. }\end{array}$ & 4.05 & 4.39 & 0.014 \\
\hline 31 & $\begin{array}{l}\text { I can provide authentic language models for } \\
\text { the students during the class. }\end{array}$ & 3.52 & 4.38 & 0.000 \\
\hline 32 & I am proficient in English communication. & 2.79 & 3.87 & 0.000 \\
\hline 33 & $\begin{array}{l}\text { I am able to teach in English fluently in class } \\
\text { continuously. }\end{array}$ & 2.95 & 3.97 & 0.000 \\
\hline
\end{tabular}

\section{Discussion}

\subsection{Demographic Profile of Zhuangang English Teachers}

Accounting for $1 / 3$ of the whole group of English teachers, Zhuangang English teachers is an important part of the English teachers in primary schools of China. This result lends support to You's (2016) conclusion that zhuangang English teachers account for $32.5 \%$ of the primary school English teachers. From the aspect of gender rate, years of teaching (including teaching of English and other subjects) and the grades they teach, there is not much difference between zhuangang English teachers and the whole group of English teachers. What is obvious is that, zhuangang English teachers' experience of teaching is shorter than non-zhuangang English 
teachers. In terms of their educational background, only $70.5 \%$ of zhuangang English teachers have bachelor's degree (part-time) and most of them did not major in English in college. That is to say, their English proficiency stays at what they have learned in the high school.

\subsection{Comparison of Perceptions of Professional Identity between Zhuangang and Non-zhuangang English Teachers}

According to the result of data analysis, a significant difference of perceptions of professional identity can be observed between zhuangang and non-zhuangang English teachers and non-zhunagang English teachers have a stronger perception of their professional identity than zhuangang English teachers. Through analyzing the 34 items of the questionnaire individually, we try to figure out the reasons that may contribute to the gap in their perceptions of the professional identity and it can be classified into 4 sorts: their different opinions about being an English teacher, different views about English learning, distinct views about English teaching, and most importantly, the gap in their English proficiency.

\subsubsection{Unsatisfactory English Proficiency}

The most important reason responsible for the gap between zhuangang and non-zhuangang English teachers is zhuangang English teachers' inadequate English proficiency. It is illustrated in item 31 (I can provide authentic language models for the students during the class), 32 (I am proficient in English communication) and 33 (I am able to teach in English fluently in class continuously). In all of these 3 items, zhuangang English teachers are almost one point lower than non-zhuangang English teachers in the mean score and all the $p$ values are equivalent to 0.000 , indicating a remarkably significant difference between zhuangang and non-zhuangang English teachers in their English proficiency.

\subsubsection{Opinions about being an English Teacher}

The participants' different views about being an English teacher can be observed from their different attitudes towards their own occupation of being an English teacher. It can be seen from item 3 (While making self-introductions, I am pleased to say that I am an English teacher) and item 8 (I care about others' opinions about English teachers). In these two items, non-zhuangang English teachers score much higher than zhuangang English teachers and there are significant differences between them. In other words, compared with zhuangang English teachers, non-zhuangang English teachers are much proud of their own occupation and are more concerned about how others look at them. According to Day et al. (2006), teachers need to have a clear awareness of agency about who they are and what they do because their sense of professional identity is closely related with this and the lack of stability about being neither one nor the other is likely to result in problems (Antonio \& Domingo, 2006). For zhuangang English teachers, however, it is not easy to shift from the role of being the teacher of the subjects that they used to teach and this kind of uncertainty and instability is likely to cause their weak sense of professional identity. Antonio and Domingo (2006) also state that while reconstructing one's new identity, they must experience a long and physically arduous process of transcending their own previous identity. For zhuangang English teachers, they have to build up their new identity of being an English teacher, including new opinions about who they are and what they should do through a long process.

\subsubsection{Views about English Learning}

Another reason that may cause the gap in the perceptions of zhuangang English teachers' teacher identity may be their different views about English learning, which is indicated from item 14 (Knowing about English-speaking countries' culture is a necessity to learn English well) and 15 (English learning is actually a process of knowledge construction). Non-zhuangang English teachers surpass zhuangang English teachers in these two items. As MacDonald, Badger and Dasli (2006) put it, when a language learner is learning a new language, not only the new sets of values and beliefs are opened up to them, but also the previous "situated" ones are challenged. English learning is not just memorizing of words, collocations and sentences but a discarding, selecting and integrating process of the target language and culture. Moreover, with the growing influence of the teacher-centered learning philosophy, it is emphasized that learners should be the creators or constructors of their own knowledge (Mino-Garces, 2009). The two groups of teachers differ notably on these points. For the zhuangang English teachers, a lack of knowledge about the nature and characteristics of students' English learning may result in their different views about English learning and lead to a weaker sense of their professional identity.

\subsubsection{Views about English Teaching}

The third reason lies at their different views about English teaching, which is actually what is suggested in item 18 (I take primary school pupils' learning characteristics into consideration in my teaching practice) and item 30 
(English teaching in the primary school has the subject's own characteristics). Zhuangang English teachers score lower than non-zhuangang English teachers in those two items. This finding is consistent with Beijaard, Verloop and Vermut's (2000) statement that teachers' experiences concerning subject matter and pedagogical aspects have bearings on their perceptions of professional identity. It follows that zhuangang English teachers' weak command of pedagogical theories and understanding of learning characteristics affect their teaching practice and thus their professional identity.

\subsection{Implications for Teacher Education}

The importance of teacher education towards identity development has been verified in recent literature (Beauchamp \& Thomas, 2009; Watson, 2006). Through the investigation of the present paper, the reasons behind zhuangang English teachers' weaker perceptions of their professional identity are revealed and this may shed light on future teacher education programs. Firstly, compared with non-zhuangang English teachers, more training opportunities should be given to zhuangang English teachers to improve their English proficiency in order to shorten the big gap between zhuangang and non-zhuangang English teachers in terms of their English proficiency levels. Secondly, apart from their English proficiency, pedagogical theories should also be introduced in the training program. Besides, the training programs should convince the zhuangang English teachers of the importance of being an English teacher by incorporating what is known about the contexts and communities that they are in. Only by enhancing their awareness of the significance of their occupation can they strengthen their own professional identity and commitment to the teaching career.

\section{Conclusion}

This research aims to figure out the profile of zhuangang English teachers in South China's Kaiping county and explore the reasons responsible for the significant difference in their perceptions of teacher identity between zhuangang and non-zhuangang English teachers. The result confirms a conclusion by previous studies that about one third of the primary school English teachers in rural areas of China are zhuangang English teachers. It also finds that the gap between zhuangang and non-zhuangang English teachers' perceptions of teacher identity is attributable to the teachers' different understandings about the profession of being an English teacher, zhuangang English teachers' shortage of pedagogical theories and knowledge of primary school pupils' learning characteristics, and zhuangang English teachers' inadequate English proficiency. It is concluded that much more attention and concerns should be given to the professional training of zhuangang English teachers. Despite the limited scope of survey, we believe the findings of this study can be tentatively extended to more comparable schools and areas in China and has implications on relevant policy-making and practices. Future research could cover more regions of the country so that a much fuller picture of zhuangang English teachers in China can be revealed. Besides, combined methods including qualitative interviews are also recommended.

\section{Acknowledgements}

This study is supported by the Chinese MOE Key Research Project of Philosophy and Social Science (15JZD048). The authors are grateful to Ms Mengxi Li for her help.

\section{References}

Abednia, A. (2012). Teachers' professional identity: Contributions of a critical EFL teacher education course in Iran. Teaching and Teacher Education, 28(5), 706-717. https://doi.org/10.1016/j.tate.2012.02.005

Ajayi, L. (2011). How ESL Teachers' Sociocultural Identities Mediate Their Teacher Role Identities in a Diverse Urban School Setting. Urban Review, 43(5), 654-680. https://doi.org/10.1007/s11256-010-0161-y

Antonio, bol í var, \& Domingo, je sús. (2006). The Professional Identity of Secondary School Teachers in Spain: Crisis and Reconstruction. Theory and Research in Education, 4(3), 339-355. https://doi.org/10.1177/1477878506069105

Beauchamp, C., \& Thomas, L. (2009). Understanding teacher identity: An overview of issues in the literature and implications for teacher education. Cambridge Journal of Education, 39(2), 175-189. https://doi.org/10.1080/03057640902902252

Beijaard, D., Meijer, P. C., \& Verloop, N. (2004). Reconsidering research on teachers' professional identity. Teaching and Teacher Education, 20(2), 107-128. https://doi.org/10.1016/j.tate.2003.07.001

Beijaard, D., Verloop, N., \& Vermut, J. D. (2000). Teachers' perceptions of professional identity: An exploratory study from a personal knowledge perspective. Teaching and Teacher Education, 16(7), 749-764. https://doi.org/10.1016/S0742-051X(00)00023-8

Day, C. (2011). Uncertain Professional Identities: Managing the Emotional contexts of Teaching. In C. Day, \& J. 
C. Lee (Eds.), New Understandings of Teacher's Work (pp. 45-64). https://doi.org/10.1007/978-94-007-0545-6

Day, C., \& Kington, A. (2008). Identity, well-being and effectiveness: the emotional contexts of teaching. Pedagogy, Culture \& Society, 16(1), 7-23. https://doi.org/10.1080/14681360701877743

Day, C., Kington, A., Stobart, G., \& Sammons, P. (2006). The personal and professional selves of teachers: stable and unstable identities. British Educational Research Journal, 32(4), 601-616. https://doi.org/10.1080/01411920600775316

Dong, Y. (2003). Are We Ready for “an Early Start in Foreign Language Learning.” Modern Foreign Languages, 26(1), 39-47.

Farrell, T. S. C. (2011). Exploring the professional role identities of experienced ESL teachers through reflective practice. System, 39(1), 54-62. https://doi.org/10.1016/j.system.2011.01.012

Gee, J. P. (2000). Identity as an Analytic Lens for Research in Education. Review of Research in Education, 25(1), 99-125. https://doi.org/10.3102/0091732X025001099

Ha, P. Le. (2007). Australian-Trained Vietnamese Teachers of English: Culture and Identity Formation. Language, Culture and Curriculum, 20(1), 20-35. https://doi.org/10.2167/lcc324.0

Hammerness, K., Darling-hammond, L., \& Bransford, J. (2005). How teachers learn and develop. In L. Darling-Hammond, \& J. Bransford (Eds.), Preparing teachers for a changing world: What teachers should learn and be able to do (pp. 358-389). San Francisco: Jossey-Bass.

Han, B., \& Liu, R. (2008). China's English Language Education at Schools: A Review and Reflection on its policies and goals. Foreign Language Teaching and Research, 40(2), 150-155.

Han, I. (2016). Conceptualisation of English Teachers' Professional Identity and Comprehension of its Dynamics. Teachers and Teaching, 602(July), 1-21. https://doi.org/10.1080/13540602.2016.1206525

MacDonald, M. N., Badger, R., \& Dasli, M. (2006). Authenticity, Culture and Language Learning. Language and Intercultural Communication, 6(3-4), 250-261. https://doi.org/10.2167/laic252.0

McLean, S. V. (1999). Becoming a teacher: The person in the process. In R. P. Lipka, \& T. M. Brinthaupt (Eds.), The Role of Self in Teacher Development (pp. 55-91). State University of New York Press.

Ministry of Education (MOE). (2001). Guanyu Jiji Tuijin Xiaoxue Kaishe Yingyu Kecheng Zhidao Yijian [The Guidance to Promote the Initiation of English Teaching in Primary Schools].

Mino-Garces, F. (2009). Learning for Life, a Structured and Motivational Process of Knowledge Construction in the Acquisition/Learning of English as a Foreign Language in Native Spanish Speakers. International Journal of English Studies, 9(1), 81-89.

MOE. (2001). Jichu Jiaoyu Kecheng Gaige Gangyao [The Guidelines for Curriculum Reform of Basic Education] (try-out version).

Namaghi, S. A. O. (2009). A data-driven conceptualization of language teacher identity in the context of public high schools in Iran. Teacher Education Quarterly, 36(2), 111-124.

Peng, M. (2003). Chuyi Xiaoxue Kaishe Yingyu Kecheng de Kexingxing [A Discussion about the Necessity of Starting English Teaching in Primary Schools]. Foreign Language World, 95(3), 63-68.

Richards, J. C. (2008). Second Language Teacher Education Today. RELC Journal, 39(2), 158-177. https://doi.org/10.1177/0033688208092182

Shu, D. (2001). Wokan Waiyu Jiaoxue Gaige [My Opinions on Reform of Foreign Language Teaching]. Foreign Language Teaching Abroad, (1), 8-11.

Trent, J. (2012). Becoming a teacher: The identity construction experiences of beginning English language teachers in Hong Kong. Australian Educational Researcher, 39(3), 363-383. https://doi.org/10.1007/s13384-012-0067-7

Tsui, A. B. M. (2007). Complexities of Identity Formation: A Narrative Inquiry of an EFL Teacher. TESOL Quarterly, 41(4), 657-680. https://doi.org/10.2307/40264401

Wan, Y. (2014). Jichu Jiaoyuzhong Yingyu Pujihuajiaoyu Qushi Fenxi [An Analysis of the Popularization Trend of English Teaching in Primary Education]. Daqing Social Sciences, 184(3), 144-145.

Wang, Q. (2008, September 12). Solving the Problems of English Crriculum Reform in the Way of Innovation. 
China Education Daily, pp. 1-3.

Wang Qiang. (2010). The practical exploration into the collaborative active research between universities and basic education teachers. Curriculum, Teaching Material and Method, 30(12), 87-93.

Watson, C. (2006). Narratives of practice and the construction of identity in teaching. Teachers and Teaching, 12(12), 509-526. https://doi.org/10.1080/13540600600832213

$\mathrm{Xu}, \mathrm{Y}$. T. (2014). Becoming researchers: A narrative study of Chinese university EFL teachers' research practice and their professional identity construction. Language Teaching Research, 18(2), 242-259. https://doi.org/10.1177/1362168813505943

Xun, Y., Sun, L., \& Peng, F. (2014). Formulation and Validation of a Teacher Identity Inventory for EFL Teachers. Shandong Foreign Language Journal, 162(5), 61-67.

Yang, S., \& Bautista, D. D. (2008). Reflection, arts, and self - inquiry: a letter to other for negotiating Korean English teacher identity. Reflective Practice, 9(3), 293-305. https://doi.org/10.1080/14623940802207170

You, H. (2016). Constructing District Professional Identity, Exploring New Models of Teacher Development. Journal of Curriculum and Instruction, (5), 91-93.

Yu, J. (2011). Review and Reflection on Curriculum Reform of Basic Education in Mainland China since the New Century. Research in Teaching, 34(4), 77-79.

Zhang, Z. (2005). Woguo Waiyu Jiaoyu de Guoqing Tedian [Foreign Language Education Characteristics in China]. Foreign Language Teaching and Research in Basic Education, 58(12), 16-21.

\section{Appendix}

\section{3 items in the questionnaire enquiring the primary school English teachers' identity}

1. I finish my job of English teaching every day seriously.

2. I can well manage my students in classes.

3. When making self-introductions, I am pleased to say that I am an English teacher.

4. I feel pleased when hearing or seeing words praising the occupation of teacher.

5. I can converse with the school equally.

6. I like, care and respect students from the bottom of my heart.

7. I devise the class activities according to primary school pupils' characteristics.

8. I care about others' view about English teachers.

9. I build up harmonious relationship with colleagues positively.

10. Primary school English teachers are important for the pupils' personal growth.

11. I keep a good relationship with the students.

12. Teachers' work is important for students' growth and development.

13. I think high of students' development of ability and learning strategies since they are the teaching subjects.

14. Knowing about English-speaking countries' culture is a necessity to learn English well.

15. English learning is a process of knowledge construction.

16. Teaching method is important for students' English learning.

17. Foreign language teaching reform is conducive to improving my professional level.

18. I take primary school pupils' learning characteristics into consideration in my teaching practice.

19. I undertake the teaching task actively.

20. I am enthusiastic about my work.

21. I feel pleased when committing myself to the work.

22. I feel powerful and energetic while working.

23. While in difficulty, I can always get help from the school. 
24. The school really cares about my welfare treatment.

25 . The school feels proud of my contribution in my work.

26. The school tries its best to make my job joyful.

27. I care about whether my students can get a high score in the examinations.

28. I am in support of primary school English teaching reform.

29. I think that English can only be acquired in a communicative environment.

30. English teaching in the primary school has the subject's own characteristics.

31. I can provide authentic language models for the students during the class.

32. I am proficient in English communication.

33. I am able to teach in English fluently in class continuously.

\section{Copyrights}

Copyright for this article is retained by the author(s), with first publication rights granted to the journal.

This is an open-access article distributed under the terms and conditions of the Creative Commons Attribution license (http://creativecommons.org/licenses/by/4.0/). 